\title{
The prevalence of pancreatic neuroendocrine neoplasms with dedifferentiation during their natural history
}

EP618

Krystallenia Alexandraki, Maria Kaltsatou, Maria Chrysochoou, Georgios Nikolopoulos,

Panagiotis Moschouris, Anna Angelousi, Vasiliki Mavroeidi, Marina Tsoli, Eleftherios Chatzellis, Georgios Boutzios, Gregory Kaltsas

Department of Pathophysiology, Laikon Hospital, Medical School, National and Kapodistrian University of Athens, Greece.

\section{Objectives}

* Neuroendocrine neoplasms (NENs) are neoplasms with a slow progression and a 5-year survival $77-95 \%$.

* Secondary deposits of NENs may dedifferentiate during the natural history of the disease, presenting a more aggressive biological behaviour.

* The aim of the study was to investigate the prevalenve of secondary foci dedifferentiation of pancreatic NENs ( $p$ NENs).
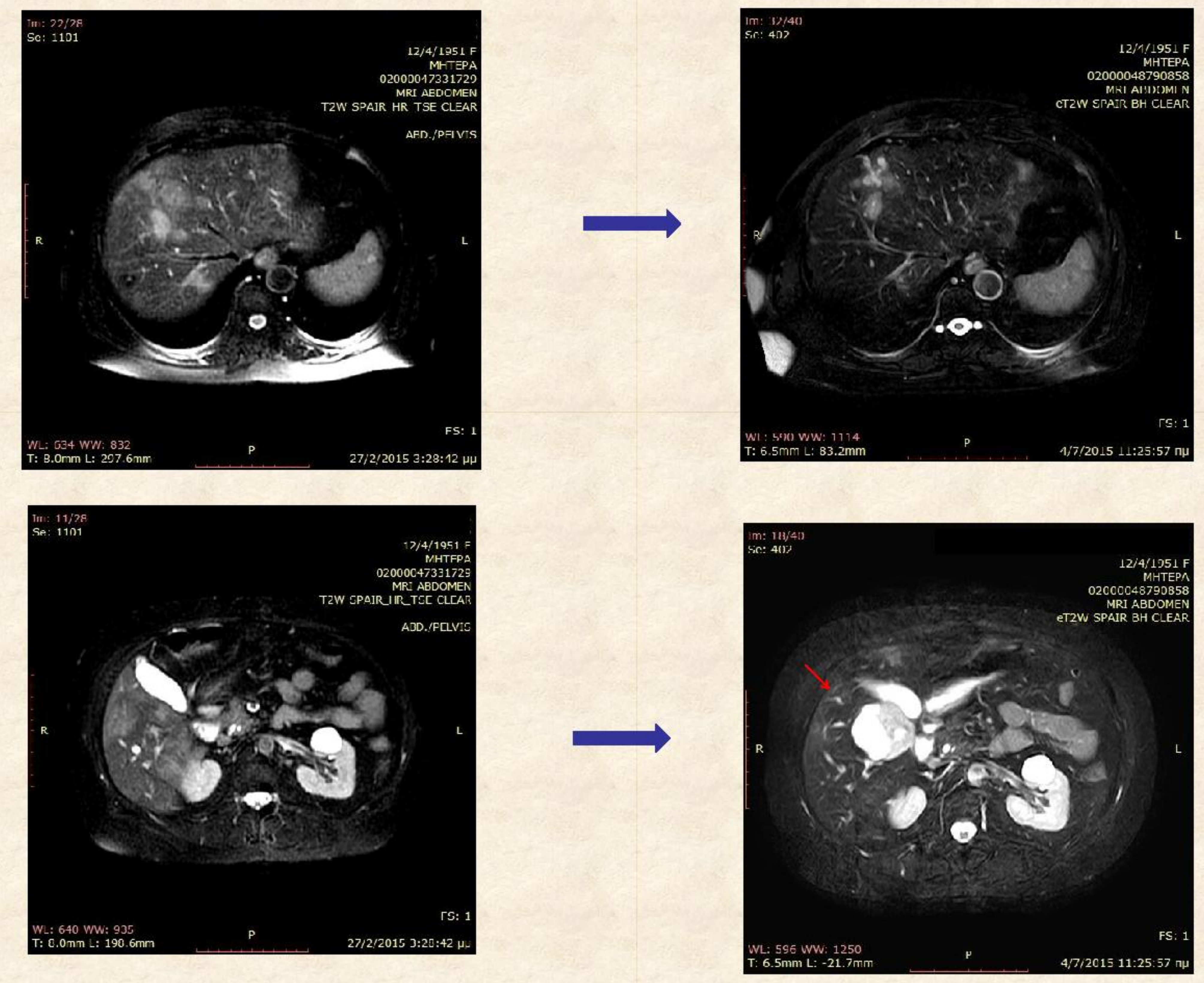

Improvement of the liver metastases after treatment with temozolomide/capecitabine. New lesion (ki $67=50 \%$ )
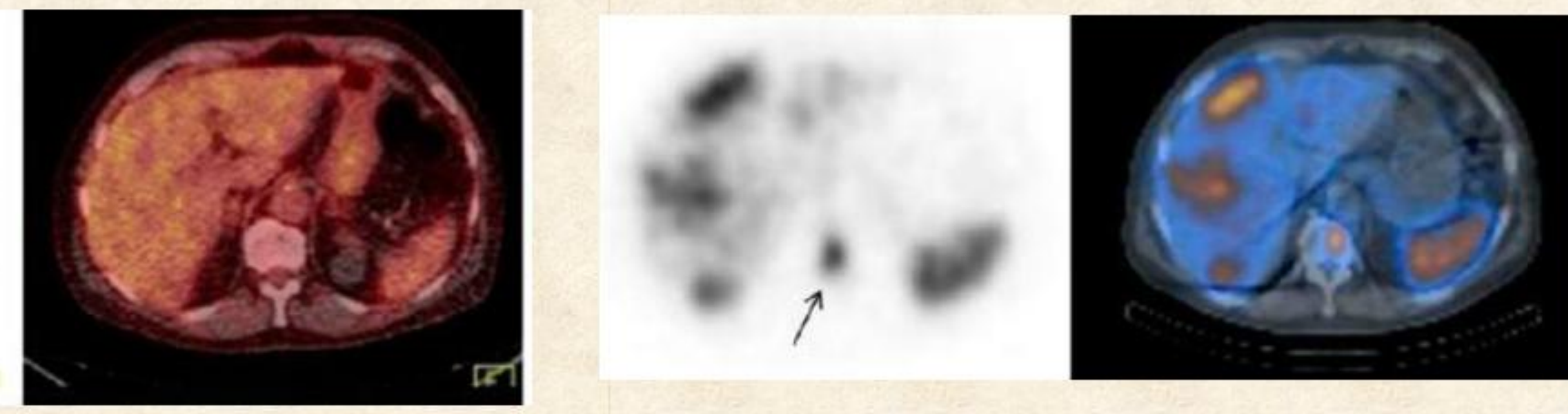

Patient with grade $1($ ki67<2\%) ileal NEN. Negative 18FDG-PET/CT and positive somatostatin receptor scintigraphy (SRS)
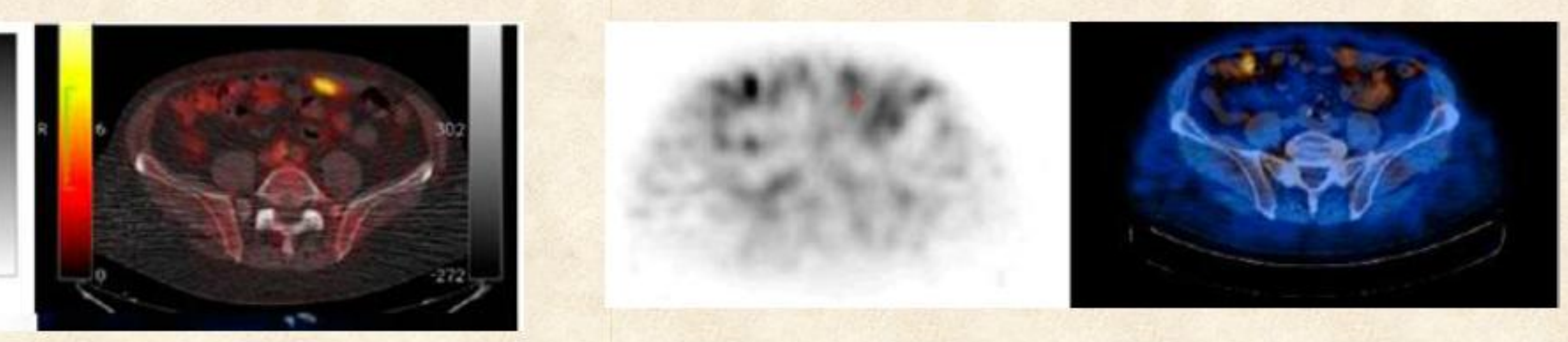

Patient with grade 3 (ki67=95\%) colon NEN. Positive 18FDG-PET/CT and negative SRS.

\section{Methods}

* From the NENs database of 414 patients, $160(38,6 \%)$ had pNENs.

* Patients with dedifferentiation were identified by a new biopsy of metastatic foci and a high proliferation index Ki-67 MIBI (\%) that indicated a poorly differentiated NENs that originated from a primary site with a lower Ki-67.

\begin{tabular}{|c|c|c|c|c|c|c|}
\hline \multicolumn{7}{|c|}{ Results } \\
\hline \multicolumn{7}{|c|}{$\begin{array}{l}5(3 \%) \text { patients, all } \\
\text { dedifferentiation } \\
* \text { Mean age } 58.8 \pm 4.3 y r s\end{array}$} \\
\hline \\
\hline \multirow[t]{6}{*}{ Gender } & $\begin{array}{l}\text { Age of } \\
\text { diagnosis }\end{array}$ & $\begin{array}{l}\text { Primary } \\
\text { tumor }\end{array}$ & $\begin{array}{l}\text { Stage at } \\
\text { diagnosis }\end{array}$ & Ki67/grade & $\begin{array}{l}\text { Secondary } \\
\text { deposits }\end{array}$ & $\begin{array}{l}\text { New } \\
\text { ki67/grade }\end{array}$ \\
\hline & 55 & Pancreas & IV & $5 \% / 2$ & Liver & $70 \% / 3$ \\
\hline & 54 & Pancreas & III & $1 \% / 1$ & $\begin{array}{l}\text { Liver, } \\
\text { ovaries, } \\
\text { breast }\end{array}$ & $51 \% / 3$ \\
\hline & 62 & Pancreas & IV & $5 \% / 2$ & $\begin{array}{l}\text { Liver, } \\
\text { bones }\end{array}$ & $50 \% / 3$ \\
\hline & 64 & Pancreas & IV & $5 \% / 2$ & Liver & $30 \% / 3$ \\
\hline & 59 & Pancreas & IV & $5 \% / 2$ & Liver & $60 \% / 3$ \\
\hline
\end{tabular}

* 2 with functional syndrome

* 1 carcinoid syndrome

* 1 insulinoma

* $2(40 \%)$ underwent surgery

* $1^{\text {st }}$ line treatment

- 2(40\%) Somatostatin analogs (SAs)+everolimus

* $1(20 \%)$ SSAs + everolimus + Peptide receptor radionuclide therapy (PRRTs)

* $1(20 \%)$ SSAs

* 1(20\%) follow up

* Progression-free survival (PFS) after $1^{\text {st }}$ line treatment

* 39.3 25.9 months

* PFS after further therapies (8 lines)

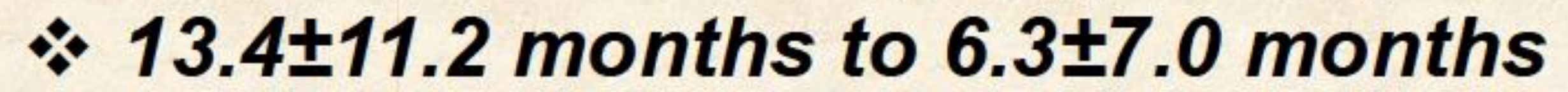

* Mean time from diagnosis until dedifferentiation

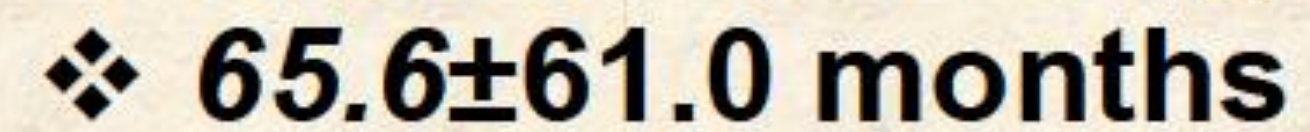

* 2(40\%) patients deceased

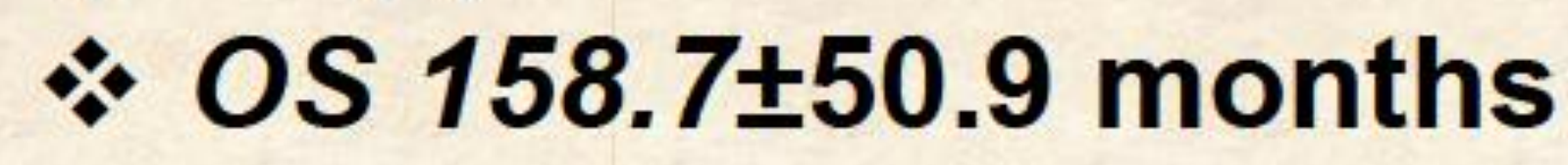

* Total follow up

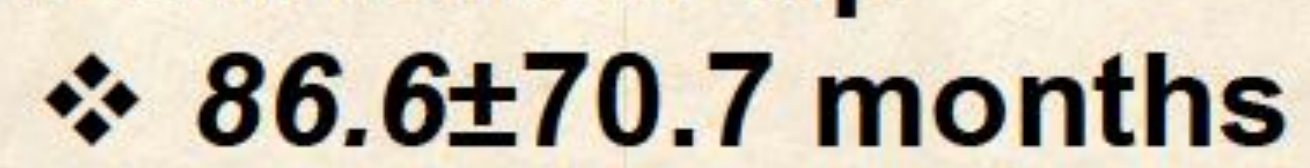

Table 2: Total survival of all patients with pNENs 5yr survival 10yr survival

$\begin{array}{lll}\text { Patient with pNENs } & \mathbf{8 2 , 8} \% & 48,3 \%\end{array}$

* From the patients with dedifferentiation 2 were alive after 5 and 10 years of follow up

* 1 deceased after 10.2yrs

* 1 deceased after 16.2yrs

\section{Conclusions}

* The dedifferentiation of NENs implies a more aggressive biological behaviour and worse overall survival despite the use of different therapies.

References

- Binderup et al. (2010). The Journal of Nuclear Medicine, vol.51, No. 5

- Poiana et al. (2013). Rom J Morphol Embryol, 54(1): 201-203.

Tang et al. ((2015). Clinical Cancer Research;2015 